\title{
Team Mindfulness and Employee Moral Efficacy: The Moderating Effect of Team Bottom-Line Mentality
}

\author{
Yang $\mathrm{Li}^{1, \mathrm{a}}$, Han Ren ${ }^{2, \mathrm{~b} *}$ \\ ${ }^{1}$ Business School, Sichuan University Chengdu, China \\ ${ }^{2}$ Business School, Sichuan University Chengdu, China
}

\begin{abstract}
Different from the previous studies that mainly focused on the mindfulness at the individual level, this research explores the effect of team mindfulness on employee moral efficacy, and considers the influence of the interaction between team bottom-line mentality (BLM) and team mindfulness on employees' moral efficacy. Results from three-wave surveys of 275 employees indicated that: the team BLM will weaken the positive relationship between team mindfulness and employees' moral effectiveness. This research advances the current understandings of the influencing process between team mindfulness and employees' moral efficacy by identifying the moderating role of team BLM, and casts the spotlight on the impact mechanism among team mindfulness, team BLM, and employees' moral efficacy at the team level. Theoretical and practical implications are also discussed.
\end{abstract}

\section{Introduction}

Organizations are operating in increasingly complex global environments, which also pose difficult moral challenges for employees of the organization ${ }^{[7]}$. Scholars have confirmed that moral efficacy will be positively associated with moral motivation and moral action ${ }^{[5]}$. Accordingly, 'how to facilitate employees' moral efficacy' has drawn increasing interests of scholars and practitioners in the organizational settings. One remarkable antecedent, employees' mindfulness, has been confirmed to exert positive effects on employees' attitudes and behaviors, however, what remains unknown is whether the team mindfulness has predictive effects on employees' moral efficacy.

Recently, an increasing number of managers and researchers are beginning to realize the importance of team mindfulness in the process of team development. Previous studies have shown that team mindfulness negatively affects team relationship conflicts and further helps to attenuate the intensity of team conflicts and their negative effects ${ }^{[18]}$. As a collective mutual belief, team mindfulness can affect the operation of the team and help individuals deal with things and teammates more objectively ${ }^{[17]}$. Employees in mindful teams are less likely to be affected by conflicts ${ }^{[1]}$ which affects employees' perceptions of moral issues and their ability to deal with moral issues ${ }^{[18]}$. Therefore, this research predicts that employee moral efficacy is positively related to team mindfulness.

Moreover, teams with high level of bottom-line mentality (BLM) believes that bottom line results are the most important, while disregards other organizational considerations that do not seem directly and immediately relevant to the bottom line (e.g., interpersonal relationships between teammates ${ }^{[9]}$; upholding ethics ${ }^{[2]}$ ). Thus, we suggest that team BLM will negatively moderate the relationship between the team mindfulness and the employee moral efficacy.

\section{Theoretical Background and Hypotheses}

\subsection{Team mindfulness and employee moral efficacy}

Mindfulness, which refers to "a receptive attention to and awareness of present events and experience" [3], has been widely researched in the field of management. Yu et al (2018) ${ }^{[18]}$ defined team mindfulness as "a shared belief among team members that interactions are characterized by awareness and attention to present events, and by experiential, nonjudgmental processing of within-team experiences". Team mindfulness is a team-level property, not an aggregation of individual mindfulness [18]. According to Yu and Zellmer-Bruhn 's (2018) ${ }^{[18]}$, team mindfulness negatively relates to team conflicts. Team mindfulness provides attention stability ${ }^{[18]}$, so the mindful team focuses on task goals and pays less attention to the interference of thoughts and activities unrelated to the task ${ }^{[12]}$, thus reducing team conflicts. In general, team mindfulness creates an internal environment that is less prone to conflicts and limits the escalation of conflicts.

Moral efficacy is defined as "an individual's belief in his/her capabilities to organize and mobilize the motivation, cognitive resources, means, and courses of

b*Corresponding author. Email address: renhan@scu.edu.cn 
action needed to attain moral performance, within a given moral domain, while persisting in the face of moral adversity" [8]. Research shows that team conflicts can affect employee moral efficacy ${ }^{[18]}$. In a team that has experienced relationship conflicts, team members may not be able to recognize and systematically deal with moral issues, and they may not be able to respond to relationships in a morally desirable way ${ }^{[18]}$, resulting in unethical behaviors ${ }^{[6]}$. In sum, conflicts in relationships within a team will reduce employee moral efficacy.

In general, teams with higher levels of team mindfulness face less intense relationship conflicts, and employee moral efficacy is affected by relationship conflicts at a lower level. Therefore, we propose that:

HI: Team mindfulness is positively related to employee moral efficacy.

\subsection{The moderating effect of team BLM}

Greenbaum et al. (2012) [9] defined BLM as "onedimensional thinking that revolves around securing bottom-line outcomes to the neglect of competing priorities". And Greenbaum, Bonner and Mawritz, et al. (2020) ${ }^{[11]}$ extended the BLM to the team level, "group BLM exists when work-group members share a singular focus on achieving bottom-line outcomes to the exclusion of competing priorities".

Employees in teams with high levels of BLM tend to approach the bottom-line with a one-dimensional, winlose mentality, which makes it easy for them to regard anyone as an opponent who obstructs their own bottomline results ${ }^{[10]}$. Therefore, employees in a team with a high BLM may ignore the importance of interpersonal relationship and tend to treat their team members as competitors and sacrifice the interests of teammates to achieve their bottom-line results. Then, the hostile relationship between employees is promoted which may lead to relationship conflicts. Finally, employees' moral effectiveness is destroyed. As a result, the following assumption is made:

H2: Team BLM moderates the strength of the relationship between team mindfulness and employee moral efficacy, such that the relationship is stronger (weaker) when team BLM is low (high).

\section{Methods}

\subsection{Sample and procedures}

This study collected data from a large state-owned coal company in Northern China. To reduce the potential risk of common method bias, a three-time lagged design was employed to test the hypothesized relationships among variables ${ }^{[16]}$. The questionnaires of three-wave surveys were distributed to the employees with the assistance of human resources manager. The time interval between each round of survey was one month. In the end, 275 valid matched questionnaires were obtained. Among 275 respondents, $91.1 \%$ were male and $8.9 \%$ were female. Their average age is 39.05 .

\subsection{Measures}

All items were measured on a 7-point Likert scales ranging from 1 "strongly disagree" to 7 "strongly agree."

Team mindfulness. We used Yu and Zellmer- Bruhn’s (2018) ${ }^{[18]} 10$-item Team Mindfulness Scale, which includes items such as: "The team experiences moments of peace and ease, even when things get hectic and stressful.” This scale has two dimensions. Consistent with Yu and Zellmer-Bruhn (2018) ${ }^{[18]}$, we combined them into one variable for their strong correlation. The Cronbach's alpha of this scale was 0.608 .

Employee moral efficacy. We employed the three-item moral efficacy scale developed by Hannah and Avolio (2011) ${ }^{[8]}$. Employees were asked to evaluate their own moral efficacy. A sample item is "I am confident that I can do the right thing when faced with moral dilemmas". The Cronbach' alpha of this scale was 0.720

Team bottom-line mentality. We used the four-item scale developed by Greenbaum et al.'s (2012) ${ }^{[9]}$ to measure team BLM, but we changed the designation to the department, which is consistent with past team level research. A sample item is "My team Treats the Bottom line as more important than Anything else”. The Cronbach' alpha of this scale was 0.835 .

Control variables. We included several individual's demographic information as control variables that might affect the relationships depicted in our model: gender, age, organizational tenure, education level, and position in the organization.

\section{Results}

\subsection{Confirmatory factor analyses (CFA) and descriptive statistics}

We conducted a series of CFA analyses to evaluate the distinctiveness among the study variables. Three variables were employed in our study: team mindfulness, team BLM, and employee moral efficacy. To reduce inflated measurement errors resulting from multiple items for the latent variable, consistent with Nasser-Abu Alhija \& Wisenbaker (2006) ${ }^{[14]}$, two-item parcels were created for team mindfulness in line with its two dimensions. Using data obtained from the three-round questionnaires, we examined two alternative models against the baseline three-factor model (M1). As shown in Table 1, M1 fitted the data well $\left(\chi^{2} / d f=3.186\right.$, $\mathrm{SRMR}=.077$, $\mathrm{RMSEA}=.089$, $\mathrm{CFI}=.943$, IFI $=.944$, $\mathrm{NNFI}=.902$ ) and provided substantial improvement in fit indices over alternative models (M2-3).

The means, standard deviations, and correlations among the study variables are presented in Table 2. Most of the variables had correlations in the expected direction. 
Table1. Comparison of alternative measurement models

\begin{tabular}{|c|c|c|c|c|c|c|c|c|}
\hline Models & $\chi^{2}(d f)$ & $\chi^{2} / d f$ & $\triangle \chi^{2}$ & SRMR & RMSEA & CFI & IFI & NNFI \\
\hline 1. Three factors: TM, TBLM, EME & $66.90(21)$ & $3.186^{* *}$ & -- & .077 & .089 & 943 & 944 & 902 \\
\hline 2. Two factors: TM and TBLM combined into one factor & $77.34(23)$ & $3.362^{* *}$ & $10.435^{* *}$ & .084 & . 093 & 932 & .934 & 894 \\
\hline 3. One factor: Three factors combined into one factor & 255.95(24) & $10.665^{* *}$ & $189.050^{* *}$ & 147 & 188 & 712 & 716 & 568 \\
\hline
\end{tabular}

${ }^{* *} p<.01 . \mathrm{TM}=$ Team mindfulness, TBLM $=$ Team bottom line mentality, EME = Employee moral efficacy.

Table2. Means, standard deviations, and correlations of all variables involved in the study

\begin{tabular}{llllllllll}
\hline Variables & $\mathbf{M}$ & SD & $\mathbf{1}$ & $\mathbf{2}$ & $\mathbf{3}$ & $\mathbf{4}$ & $\mathbf{5}$ & $\mathbf{6}$ & $\mathbf{7}$ \\
\hline 1 gender & 1.09 & 0.29 & & & & & & & \\
2 age & 39.05 & 8.34 & .050 & & & & & & \\
3 tenure & 15.26 & 9.31 & $.142^{*}$ & $.859^{* *}$ & & & & & \\
4 education & 2.20 & 1.08 & $.232^{* *}$ & -.021 & .089 & & & & \\
5 position & 1.32 & 0.61 & $.133^{*}$ & $.175^{* *}$ & $.222^{* *}$ & $.588^{* *}$ & & & \\
6 Team mindfulness & 4.34 & 0.70 & 0.08 & -.097 & .012 & $0.146^{*}$ & -.055 & & \\
7 Employee moral efficacy & 4.88 & 1.17 & .062 & -.029 & .006 & $.203^{* *}$ & $.185^{* *}$ & $0.203^{* *}$ & \\
8 Team BLM & 3.97 & 1.31 & .004 & $.126^{*}$ & .064 & -.088 & .081 & $-0.516^{* *}$ & .103
\end{tabular}

Note : $\quad \mathrm{N}=275$. Cronbach’s alphas are in parentheses on the diagonal. ${ }^{*} \mathrm{p}<.05 ;{ }^{* *} \mathrm{p}<.01$; two-tailed tests.

\subsection{Tests of hypotheses}

We used hierarchical regression analysis in SPSS to test the hypotheses, and the results are shown in Table 3. According to the results of M2, consistent with H1, team mindfulness showed a positive relationship with employee moral efficacy $(\beta=0.212, p<0.01)$.
In order to test hypothesis 2, we first calculated the central values of team mindfulness and team BLM, and then constructed the interaction as team mindfulness * team BLM. We again used hierarchical regression analysis to test the hypothesis. The result in Table 3 (see M4) shows that the interaction term between team mindfulness and team BLM on employee moral efficacy is significant $(\beta=$ $-0.263, \mathrm{p}<0.01$ ), thus H2 was supported.

Table3. Hierarchy regression results of all variables in the study

\begin{tabular}{|c|c|c|c|c|}
\hline \multirow{2}{*}{ Variables } & \multicolumn{4}{|c|}{ Employee moral efficacy } \\
\hline & Model1 & Model2 & Model3 & Model4 \\
\hline \multicolumn{5}{|l|}{ Control variables } \\
\hline 1 Gender & 0.012 & 0.005 & -0.007 & -0.013 \\
\hline 2 Age & -0.087 & -0.039 & -0.055 & -0.064 \\
\hline 3 Tenure & 0.031 & -0.010 & -0.008 & 0.029 \\
\hline 4 Educational level & 0.129 & 0.080 & 0.098 & 0.069 \\
\hline 5 Position & 0.120 & $0.162^{*}$ & 0.143 & 0.117 \\
\hline \multicolumn{5}{|l|}{ Independent variables } \\
\hline 6 Team mindfulness & & $0.212^{* *}$ & $0.339^{* * *}$ & $0.331^{* *}$ \\
\hline \multicolumn{5}{|l|}{ Moderator } \\
\hline 7 Team bottom line mentality & & & $0.259^{* * k}$ & $0.310^{\text {** }}$ \\
\hline \multicolumn{5}{|l|}{ Interaction } \\
\hline 8 Team mindfulness $\times$ Team bottom line mentality & & & & $-0.263^{* *}$ \\
\hline Adjusted $\mathrm{R}^{2}$ & 0.036 & 0.075 & 0.121 & 0.183 \\
\hline$\triangle \mathrm{R}^{2}$ & 0.054 & 0.042 & 0.049 & 0.063 \\
\hline$\triangle \mathrm{F}$ & $2.949^{*}$ & $11.848^{* *}$ & $14.690^{* * *}$ & $20.338^{* *}$ \\
\hline
\end{tabular}

Note: ${ }^{*} \mathrm{p}<.05 ;{ }^{* *} \mathrm{p}<.01$; two-tailed tests.

To confirm the direction of this interaction effect, we applied conventional procedures for plotting simple slopes (see Figure 1) at one standard deviation above and below the mean of the team BLM measure. As expected, the slope of the relationship between team mindfulness and employee moral efficacy was strong for employees who assessed team BLM as low $(\beta=0.530, p<0.01)$, whereas the slope was weak for employees who assessed team BLM as high ( $\beta=0.131$, n.s.). 


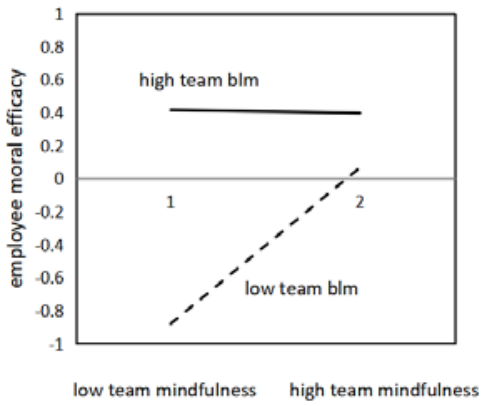

Fig 1. Interaction effect of team BLM and team mindfulness on employee moral mentality

\section{Discussion}

\subsection{Theoretical contribution.}

Previous researches on mindfulness mostly focused on the individual level. From the perspective of the team, this study explores the effect of team mindfulness on employee moral efficacy, which advances the current understandings of mindfulness from the perspective of interaction between team and individual. This research creatively combined team BLM with team mindfulness to explore the impact of their interaction on individual level variables. In conclusion, this study shows that team mindfulness positively affects employee moral efficacy, but team BLM weakens this relationship.

\subsection{Practical implications.}

This research shows that team mindfulness has a positive effect on the employee moral efficacy. This provides new ideas for companies to solve the ethical deficiency and workplace deviance of employees in the team. Companies can improve employee moral efficacy by improving the level of team mindfulness, thus reducing employees' unethical behavior. In addition, this research has also confirmed the moderating effect of the team BLM which suggest that teams should avoid the one-dimensional bottom-line mentality and focus on all the factors such as interpersonal relationship that contribute in the team process.

\section{Conclusion}

Starting from the team mindfulness, this research explored the relationship between team mindfulness and employee moral efficacy, as well as the regulating effect of team BLM. Specially, the results show that team mindfulness can positively affect employee moral efficacy, while team BLM negatively regulates the relationship between them. In this final section, we address some shortcomings of the present framework and offer suggestions for future research. The data source of this study is single, and there may be common source variance. At the same time, this research did not pay attention to the influence of variables such as team size and task interdependence, which makes our research results may be biased. We suggest that future research should select diversified data sources and pay attention to the influence of variables such as team size and task interdependence. Research on team mindfulness and team BLM is still in its infancy, and there are still many questions to be explored. We hope to promote future research on team mindfulness and team BLM by connecting team mindfulness with team BLM.

\section{References}

1. Amason, A. C., \& Sapienza, H. J. (1997). The effects of top management team size and interaction norms on cognitive and affective conflict. Journal of Management, 23(4), 495-516.

2. Anand, V., Ashforth, B. E., \& Joshi, M. (2004). Business as usual: The acceptance and perpetuation of corruption in organizations. Journal of Management Perspectives,18(2),39-53.

3. Brown, K. W., Ryan, R. M., \& Creswell, J. D. (2007). Mindfulness: Theoretical foundations and evidence for its salutary effects. Psychological Inquiry, 18, 211-237.

4. Babalola M T, Mawritz M B, Greenbaum R L, et al. (2020). Whatever It Takes: How and When Supervisor Bottom-Line Mentality Motivates Employee Contributions in the Workplace. Journal of Management, doi: 10.1177/0149206320902521

5. Erkutlu H., Chafra J. (2019). Leader's integrity and interpersonal deviance: The mediating role of moral efficacy and the moderating role of moral identity. International Journal of Emerging Markets, doi:10.1108/IJOEM-07-2018-0406

6. Felps, W., Mitchell, T. R., \& Byington, E. (2006). How, when, and why bad apples spoil the barrel: Negative group members and dysfunctional groups. Research in Organizational Behavior, 27, 175-222.

7. Hannah, S. T., Uhl-Bien, M., Avolio, B. J., \& Cavarretta, F. (2009). A framework for examining leadership in extreme contexts. Leadership Quarterly, 20(6), 897-919.

8. Hannah S T, Avolio B J, May D R. (2011). Moral Maturation and Moral Conation: A Capacity Approach to Explaining Moral Thought and Action. The Academy of Management Review, 36(4), 663-685.

9. Greenbaum R L, Mawritz M B, Eissa G. (2012). Bottom-line mentality as an antecedent of social undermining and the moderating roles of core selfevaluations and conscientiousness. Journal of Applied Psychology, 97(2), 343.

10. Greenbaum R L, Babalola M T, Quade M J, et al. (2020). Correction to: Moral Burden of Bottom-Line Pursuits: How and When Perceptions of Top Management Bottom-Line Mentality Inhibit Supervisors' Ethical Leadership Practices. Journal of Business Ethics, doi:10.1007/s10551-020-04573-7

11. Greenbaum R L, Bonner J M, Mawritz M B, et al. (2020). It is all about the bottom line: Group bottomline mentality, psychological safety, and group creativity. Journal of Organizational Behavior, doi:10.1002/job.2445 
12. Good, D. J., Lyddy, C. J., Glomb, T. M., Bono, J. E., Brown, K. W., Duffy, M. K., Baer, R. A., Brewer, J. A., \& Lazar, S. W. (2016). Contemplating mindfulness at work: An integrative review. Journal of Management, 42(1), 114-142.

13. Mayer, D. M., Aquino, K., Greenbaum, R. L., \& Kuenzi, M. (2012). Who displays ethical leadership, and why does it matter? An examination of antecedents and consequences of ethical leadership. Academy of Management Journal, 55, 151-171.

14. Nasser-Abu Alhija, F., \& Wisenbaker, J. (2006). A Monte Carlo study investigating the impact of item parceling strategies on parameter estimates and their standard errors in CFA. Structural Equation Modeling, 13, 204-228.

15. Pfeffer, J. (2016). Why the assholes are winning: Money trumps all. Journal of Management Studies, 53, 663-669.

16. Podsakoff, P. M., Mackenzie, S. B., Lee, J. Y., \& Podsakoff, N. P. (2003). Common method biases in behavioral research: A critical review of the literature and recommended remedies. Journal of Applied Psychology, 88(5), 879-903.

17. Shengmin, Liu, Huanhuan, et al. (2019). The Influence of Individual and Team Mindfulness on Work Engagement. Frontiers in psychology, doi:10:2928-2928.

18. Yu, L., and Zellmer-Bruhn, M. (2018). Introducing team mindfulness and considering its safeguard role against conflict transformation and social undermining. Academy of Management Journal, 61, 324-347. 